\title{
Digital Technologies Applied in Agriculture for Sustainable Development
}

\author{
Carmen-Valentina Radulescuu ${ }^{1}$, Maria-Loredana Popescu ${ }^{1}$, \\ Mihaela Diana Oancea Negescu ${ }^{1}$ and Dumitru Alexandru Bodislav ${ }^{1}$
}

\begin{abstract}
Recently, many articles deal with Internet and mobile phones that have penetrated all sectors of the economy, including agriculture, in the light of their benefits. Various reports, including the World Bank, describe the main benefits of new information and communication technologies and promote their greater integration into the wider economy to increase efficiency by completing other production factors and fostering innovation, for example, drastically reducing transaction costs. The article analyzes recent literature but also presents novelty elements that emerged from questions such as the risks associated with new technologies considering that there are not enough studies in the field confirming, on the one hand, the benefits but also the losses caused by them.
\end{abstract}

Keyword: New technology, agriculture, innovation

\section{Introduction}

In the globalization era, modern agriculture reflects an extremely complex activity in which agricultural production is directly dependent on the continuous supply of energy and resources such as intensive mechanization and agrochemical development to fertilize crops and to combat weeds and pests(Sorin Burlacu, Gutu, \& Matei, 2018).

In this context, the environment has suffered and scientists have tried to find solutions to reduce the impact of intensive agriculture on the natural factors that humanity itself depends on. Thus, based on technology innovation, so-called "precision agriculture" or "intelligent agriculture" have emerged, providing tools to reduce pollution and even costs. (Altieri et al., 1983, Cox, 2002).

The concept of precision agriculture, based on information technology, becomes an attractive idea for managing natural resources and achieving the modern development of sustainable agriculture (Burlacu, S., Bodislav, D. A., \& Rădulescu, C. V., 2018). This brings agriculture into the "digital and information" era. Practice has expanded smoothly throughout the world, including some developing countries (Bran, F., Alpopi, C., \& Burlacu, S. (2018). The basic principle of soil and crop management in agriculture is certainly not new. It was called "intensive and meticulous cultivation" by the Chinese people (Maohua, W., 2001).

Increasing use of information and communication technology (ICT) in agriculture (Rădulescu, C. V., Bodislav, D. A., \& Burlacu, S., 2018), the development of unmanned aerial vehicles with autonomous flight control (Floreano D, Wood RJ, 2015) along with the development of light and powerful hyperspectral cameras that can be used for to calculate the biometry of crop development and fertilization (Li F. et al., 2014, Bareth G et al., 2015) opens the field for modern farm management (Burlacu, S., \& Jiroveanu, D. 
C. 2011)..

In the control of this precision farming, remote detection techniques are generally used(S Burlacu, Bodislav, \& Rădulescu, 2018). These information technologies are based on the development of digital image processing, focusing mainly on crop identification (Keefe and Draper, 1986), harvesting (Anquar et al., 2001), weed detection in seed samples (Granitto et al. 2002) or in open fields (Pérez et al., 1997) and testing and grading of seed quality (Dell'Aquila, 2007). In this case, the needs for development and improvement of seed quality tests are different, as analyzed by Hampton (1995).

Farmers need information to expect the speed and uniformity of seed appearance, and the seed industries need special tests to ensure the best seed quality levels for production and marketing purposes(Rădulescu, Dobrea, \& Burlacu, 2018). Seed banks dedicated to ex-situ conservation of biodiversity require routine germination testing procedures prior to renewal of high-quality preserved hatches in cold storage with the primary objective of avoiding genetic erosion of plants and contributing to the preservation of agroecosystems (Clergue et al., 2005).

Furthermore, seed analysts and researchers are interested in developing new, automatic and non-destructive techniques to characterize seed with well-defined genetic and physiological features and to improve knowledge in seed biology research (Dell'Aquila, 2008).

Automatic computerized methods that use fast data capture and data processing are the most advanced methods that provide a high degree of precision in testing and sorting seed quality. Interest is growing in the development of mechanical vision systems to replace human visual inspection, generally used in germination tests in accordance with the ISTA (2005) and AOSA (2000) rules.

Understanding growth rate patterns through image analysis parameters could be a new method to determine the germination performance of several crop seed species in an automated way. As a result, new algorithms and hardware architectures need to be developed for the high-speed extraction of raw data, such as seed digital images and numerical data such as dimensional measurements, shape factors, and color space density (Dell'Aquila, 2008).

\section{Methodology of Research}

The main research method was documentary analysis followed by a diagnostic analysis through which we identified the opportunities and constraints of intelligent agriculture. The study of the specialized literature has been doubled, given the large number of works published over the last 25 years, by a visual analysis made with the help of specialized applications.

\section{Literature Review}

The agricultural field has been found in the literature since the beginning of the scientific journals. Today, only in the Web of Science we find over 146,000 archers that deal with this domain. An analysis of the titles of the papers written in scientific journals with the help of VOSviewer allowed us to identify both the common research base of 
the agricultural field, the area of interest of the researchers as well as the trends in the field (fig. no.1.).

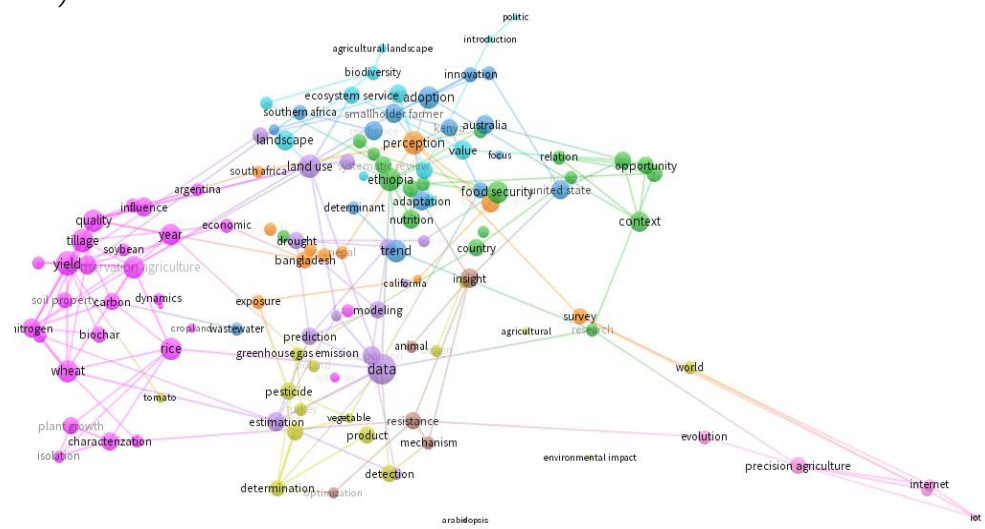

Fig. no. 1: Map of bibliographic references

Source: VOSviewer application with Web of Science data for 1975-2019

So we find that the concept of "precision agriculture" is in the trend of today's research. More than 5000 scientific papers have dealt with this topic over the past 25 years (fig. no. 2).

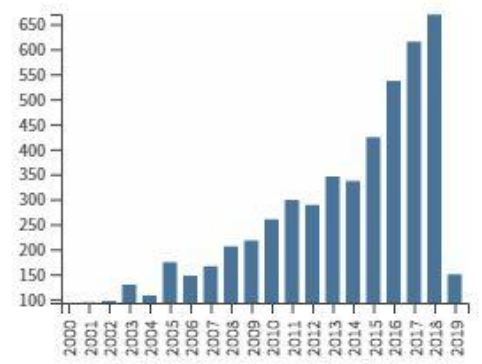

Fig. No.1: Total Publications by Year

Source: Web of Science

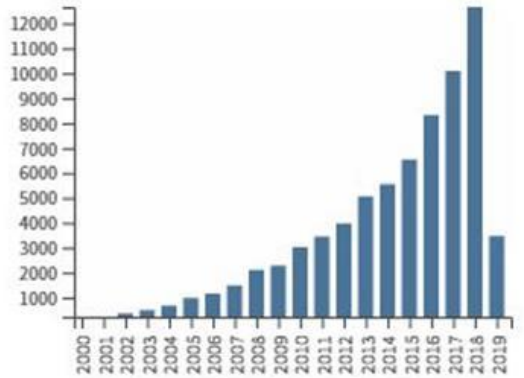

Fig. No.2: Sum of Times Cited by Year

Source: Web of Science 
Worth mentioning is that the interest in studying these works is ample, only over the past year, over 1200 works inspiring and indicating as reference research in the field of precision agriculture (fig. no.3)

In 1994, in WebofScience, the article entitled "High-Precision Agriculture is an Excellent Tool For Conservation Of Natural Resources" whose author believes that high-precision agriculture can minimize unwanted accumulation or migration of inputs, save money, and avoid interactions would reduce yields. Thus, 25 years ago it is believed that high precision may mean beyond the amount of an input with beneficial effects on the environment. In fact, high farming was considered a procedure to achieve the maximum economic yields that can make it possible to produce the necessary food and fiber on a much smaller area than is currently used (WALLACE, 1994).

Three years later, a group of New Zealand researchers also publishes the WOS article titled "Precision Agriculture: An Integration of Information Technology with Agriculture", which states that the development and integration of a range of technologies has allowed their application in agriculture. Essentially, they concerned the precision of real-time positioning through Global Positioning Systems (GPS), the use of digital maps, geographic information systems (GIS) and on-board computerized computers. A semi-quantitative benefit highlighted by researchers was the automatic storage of records, assisting with environmental standards, and keeping records managerial. In fact, at that time, many other support technologies were researched and applied in the field of agriculture(Buick, 1997).

\section{Findings}

These analyzes revealed the following features:

\section{Opportunities}

$\checkmark$ Intelligent agriculture reduces the ecological footprint by applying inputs in the required or specific quantity (chemical fertilizers, pesticides, irrigation water, etc.) causes the mitigation of undesirable effects, such as groundwater pollution as well as emissions of greenhouse gases emissions;

$\checkmark$ Valorization of Information and Communication Technology (ICT) by creating a network of sensors allowing almost continuous monitoring of the farm;

$\checkmark$ Smart agriculture can make farming more profitable for the farmer. Decreasing resource inputs will reduce costs and reduce production-related loss of inputs;

$\checkmark$ Efficient use of location-specific meteorological data allows farmers to make realistic projections of crop yields per hectare;

$\checkmark$ The use of these data in agriculture will require the initiation of legislative drafts, regulating their regime for the actors involved (Charo RA, 2015).

\section{Constraints}

Questions are raised on the ownership and use of meteorological data necessary for practicing precision agriculture;

The Government must guarantee the quality of the data so that farmers can trust their use;

In addition, ICTs will intensify challenges related to the responsibility and 
responsibility of new technologies. There must be the responsibility for poor management that leads to economic and environmental losses. In this case, who will be responsible for damage to the farmer, software vendor, or sensor manufacturer? (Charo RA, 2015);

Who will prepare farmers to use these new technologies?

The adoption of new technologies will involve significant costs for small (individual) farms, especially in developing countries. Thus, access to these technologies could only be provided by large, industrialized farms, which usually practice crops such as wheat, maize and rice on very large surfaces;

Only if industrial farms have access to these technologies increases the risk of unsustainable measures. In an industrial setting, outbreaks of diseases can be postponed by fungicides, but this comes with an increased risk of generating resistant fungal strains, which can act even more devastating once they have passed preventive measures;

Moving to industrialized societies has led to rapid falls in employment rates in agriculture to $2 \%$ and less of the population in Europe and North America. The digitization of agriculture could further influence the employment rate in agriculture generating the growth of the unemployment network (Walter A., 2017).

\section{Conclusions}

In conclusion, our paper highlights the great opportunities for analyzing data in agriculture, showing that the availability of hardware and software, data analysis techniques and methods, as well as the opening of large data sources will encourage more academic research, public sector initiatives and businesses in the agricultural sector (Kamilaris et al., 2017). Precision agriculture or smart farming is still at an early stage of development but, if the economic and social constraints are overcome by proper government support, it can be an important step in adapting to climate change. Today, research in the field focuses on the acquisition of knowledge-based and intensive information technology packages, which it analyzes through a Markov transition approach (Buick, 1997).

\section{References}

Altieri M.A., Letourneau D.K., Davis J. R. (1983) Developing sustainable agroecosystems, Bioscience 33, 45-49.

Anquar F., Mannino M.R., Casals M.L., Fougereux J.A., Demilly D. (2001) Carrot seeds grading using a vision system, Seed Sci.Technol. 29, 215-225

AOSA (2000) Rules for testing seeds, in: Association of Official SeedAnalysts (Eds.).

Bareth G, Aasen H, Bendig J, Soukkamäki J (2015) Low-weight and UAV-based hyperspectral full-frame cameras for monitoring crops: Spectral comparison with portable spectroradiometer measurements. Photogrammetrie, Fernerkundung, Geoinformation2015:69-79.

Bran, F., Alpopi, C., \& Burlacu, S. (2018). Territorial Development-Disparities between the Developed and the least Developed Areas of Romania. LUMEN Proceedings, 6(1), 146-155.

Bran, F., Rădulescu, C. V., Bodislav, D. A., \& Burlacu, S. (2019). THE ANTHROPIC PRESSURE ON THE FOREST SPACE. DYSFUNCTIONS AND RISKS IN ROMANIA. Quality-Access to Success, 20. 
Burlacu, S., Bodislav, D. A., \& Rădulescu, C. V. (2018). E-COMMERCE AND GLOBAL FOOD RESOURCES. Managerial Challenges of the Contemporary Society. Proceedings, 11(2), 48.

Burlacu, S., Gutu, C., \& Matei, F. O. (2018). Globalization - Pros and cons. Quality - Access to Success.

Burlacu, S., \& Jiroveanu, D. C. (2011). THE DEVELOPE OF SOFTWARE SOLUTION FOR SUPPLY CHAIN MANAGEMENTT. REVTSTA DE MANAGEMENT COMPARAT INTERNATIONAL/REVIEW OF INTERNATIONAL COMPARATIVE MANAGEMENT, 12(6), 140-145.

Charo RA (2015) SCIENCE AND GOVERNMENT. Yellow lights for emerging technologies. Science 349:384-385.

Cox S. (2002) Information technology: the global key to precision agriculture and sustainability, Comp. Electron. Agricult.36, 93-111.

Dell' Aquila A. (2009); (former Senior Scientist of The Institute of Plant Genetics - Cnr Bari Italy). Digital imaging information technology applied to seed germination testing. A review. Agronomy for Sustainable Development, Springer Verlag/EDP Sciences/INRA, 2009, 29 (1), pp.213-221. <hal$00886473>$

Dell'Aquila A. (2007) Towards new computer imaging techniques ap-plied to seed quality testing and sorting, Seed Sci. Technol. 38,519-538.

Floreano D, Wood RJ (2015) Science, technology and the future of small autonomous drones. Nature521:460-466.

Hampton J.C. (1995) Methods of viability and vigor testing: a critical appraisal, in: Basra A.S. (Ed.), Seed Quality. Basic Mechanism and Agricultural Implications, Food Products Press, The Haworth Press, Inc. New York, pp. 81-118.

ISTA (2005) International rules for seed testing, in: International Seed Testing association (Eds.).

Kamilaris, A., Kartakoullis, A., Prenafeta-Boldú, F., X., (2017), A review on the practice of big data analysis in agriculture, Computers and Electronics in Agriculture, Volume 143, December 2017, Pages 23 37, https://doi.org/10.1016/j.compag.2017.09.037

Keefe P.D., Draper S.R. (1986) The measurement of new characters for cultivar identification in wheat using machine vision, Seed Sci.Technol. 14, 715-724.Keys R.D. (1982) CASAS (computerized automated seed analysis system): an approach to the analysis and testing of seed J. Seed Technol. 7, 23-35.

Li F, Mistele B, Hu Y, Chen X, Schmidhalter U (2014) Reflectance estimation of canopy nitrogen content in winter wheat using optimized hyperspectral spectral indices and partial least squares regression. Euro J Agron52:198-209.

Maohua, W., (2001), Possible adoption of precision agriculture for developing countries at the threshold of the new millennium, Computers and Electronics in Agriculture, Volume 30, Issues 1-3, February 2001, Pages 45-50, https://doi.org/10.1016/S0168-1699(00)00154-X

Pérez A.J., López F., Benlloch J.V., Christensen S. (1997) Colour and shape analysis techniques for weed detection in cereal fields, First European Conference for information Technology in Agriculture, Copenhagen, 15-18 June, pp. 45-50.

Rădulescu, C. V., Bodislav, D. A., \& Burlacu, S. (2018). Demographic Explosion and its Governance in Public Institutions. Managerial Challenges of the Contemporary Society. Proceedings, 11(1), 18.

Rădulescu, C. V., Dobrea, R. C., \& Burlacu, S. (2018). The Business Management of Distress Situations. Proceedings of the 12th International Management conference "Management Perspectives in the Digital Era," 741-747.

Walter, A., Fingerb, R., Huberb, R. and Nina Buchmanna (2017), Smart farming is key to developing sustainable agriculture, 6148-6150, PNAS, June 13, vol. 114, no. 24, www.pnas.org/cgi/doi/10.1073/pnas.1707462114 